\title{
Processing of porous glass ceramics from highly crystallisable industrial wastes
}

\section{R. K. Chinnam, E. Bernardo, J. Will \& A. R. Boccaccini}

To cite this article: R. K. Chinnam, E. Bernardo, J. Will \& A. R. Boccaccini (2015) Processing of porous glass ceramics from highly crystallisable industrial wastes, Advances in Applied Ceramics, 114:sup1, S11-S16, DOI: 10.1179/1743676115Y.0000000053

To link to this article: http://dx.doi.org/10.1179/1743676115Y.0000000053

$$
\begin{aligned}
& \text { (c) } 2015 \text { The Author(s). Published by Taylor \& } \\
& \text { Francis. }
\end{aligned}
$$

里 Published online: 28 Jul 2015.

Submit your article to this journal $\pi$

LIII Article views: 234

Q View related articles ¿

View Crossmark data $₫$ 


\title{
Processing of porous glass ceramics from highly crystallisable industrial wastes
}

\author{
R. K. Chinnam ${ }^{1}$, E. Bernardo*2, J. Will ${ }^{1}$ and A. R. Boccaccini*1
}

This study was carried out to gain understanding about the sintering behaviour of highly crystallisable industrial waste derived silicate mixtures under direct heating and rapid cooling conditions. The materials used in this study were plasma vitrified air pollution control waste and rejected pharmaceutical borosilicate glass. Powder compacts sintered under direct heating conditions were highly porous; compacts with particle size $<38 \mu \mathrm{m}$ reached a maximum density of $2.74 \mathrm{~g} \mathrm{~cm}^{-3}$ at $850^{\circ} \mathrm{C}$, whereas compacts with particles of size $<100$ and $<250 \mu \mathrm{m}$ reached maximum densities of 2.69 and $2.72 \mathrm{~g} \mathrm{~cm}^{-3}$ at 875 and $900^{\circ} \mathrm{C}$ respectively. Further increase in sintering temperature resulted in a rapid decrease in density of the glass ceramics. Image analysis results were used to link the sudden drop in density to the increase in volume of microsized pores formed in the samples during sintering. In particular, compacts made from $<38 \mu \mathrm{m}$ particles sintered at $950^{\circ} \mathrm{C}$ resulted in 65 vol.-\% porosity with a pore size of $\sim 20 \mu \mathrm{m}$. Such materials can be used for sound and thermal insulation purposes.

Keywords: Porosity, Glass ceramics, Industrial waste, Silicates, Sintering, Recycling

This paper is part of a special issue on glass and ceramic composites for high technology applications (GlaCERCo)

\section{Introduction}

Municipalities incinerate waste materials in order to reduce waste volumes, recover energy and avoid excessive land filling. Municipal residues are incinerated at temperatures exceeding $850^{\circ} \mathrm{C}$, resulting in fly ash (which may be treated in situ), air pollution control residues (APCr) ${ }^{1}$ and bottom ash (also known as grate ash) as solid by products. It is estimated that the amount of waste treated in this way will increase to $20 \mathrm{Mt}$ by 2020 (UK data). ${ }^{2,3}$ The composition of APCr varies according to the source, but it is rich in silica, calcia, alumina and other oxides ${ }^{4}$ and can be modified by fluxing and melting using technologies such as the plasma vitrification process to form a stable solid. ${ }^{5}$ Such vitreous materials can be completely or partially crystallised by controlling the process parameters to form glass ceramics. ${ }^{6,7}$ Glass ceramic materials can find structural or functional applications if their processing conditions, and therefore, microstructure and properties can be controlled. In general, waste derived glass ceramics made from waste residues are found to be chemically stable and exhibit improved mechanical and functional properties in comparison with the parent glass. ${ }^{6,7,8}$

Porous glass ceramics can find applications in sound insulation, thermal insulation and also as lightweight aggregates in concrete. ${ }^{8}$ For example, Garcia et al. ${ }^{9}$ used slag from aluminium recycling with combinations of

${ }^{1}$ Institute of Biomaterials, Department of Materials Science and Engineering, University of Erlangen-Nuremberg, Erlangen D-91058, Germany

${ }^{2}$ Department of Industrial Engineering, University of Padova, 35131 Padova, Italy

*Corresponding authors, emails aldo.boccaccini@ww.uni-erlangen.de; enrico.bernardo@unipd.it other wastes to prepare a porous material for acoustic insulation. Another interesting application was discussed by Albertini et al. ${ }^{10}$ who developed a porous glass ceramic made of residues to eliminate dead zones in chemical-biological reactors. The intent was to exploit the surface porosity of inert glass ceramics to enhance the mixing of chemicals. A study performed on plasma vitrified waste (PVW) by Roether et al. ${ }^{11}$ resulted in a bulk glass ceramic that exhibited complete crystallisation when processed at $950^{\circ} \mathrm{C}$ for $120 \mathrm{~min}$.

In the present study, a similar kind of PVW derived from APCr was mixed with borosilicate glass (BSG) residues from the pharmaceutical industry to develop a new family of porous glass ceramics. The influence of sintering parameters on density changes and on microsized porosity formation in the sintered body was investigated. The mechanisms responsible for the evolution of micron sized pores in the sintered bodies were also examined. An additional objective of this study was to investigate the reduction of processing time (and consequently total energy consumed) required to fabricate the final glass ceramic product based on optimisation of the processing conditions, which is discussed in detail elsewhere. ${ }^{12}$

\section{Materials and methods}

Plasma vitrified waste and rejected pharmaceutical BSG (provided by Nuova OMPI, Italy) were used as raw materials. As received PVW (15 wt- $\% \mathrm{Al}_{2} \mathrm{O}_{3}-32.9$ wt- $\% \mathrm{CaO}-4.6$ wt- $\% \mathrm{Fe}_{2} \mathrm{O}_{3}-1.4$ wt- $\% \mathrm{MgO}-40.9$ wt$\% \mathrm{SiO}_{2}-1.7$ wt- $\left.\% \mathrm{TiO}_{2}\right)^{11}$ and $\mathrm{BSG}\left(5 \mathrm{wt}-\% \mathrm{Al}_{2} \mathrm{O}_{3}-10.5\right.$ wt- $\% \mathrm{~B}_{2} \mathrm{O}_{3}-1.5$ wt- $\% \mathrm{CaO}-7$ wt- $\% \mathrm{Na}_{2} \mathrm{O}-75$ wt- $\% \mathrm{SiO}_{2}$ ) were crushed individually in a Retsch BB51 crushing 
device; the process was repeated $\sim 4$ times with a decreasing gap between crushers. The fine powder obtained was graded into particle size fractions of $<250-100,100-38$ and $<38 \mu \mathrm{m}$ using sieves. Of the total crushed powder, $15-20 \mathrm{wt}-\%$ was $<38 \mu \mathrm{m}$ in particle size.

Plasma vitrified waste $+10 \mathrm{wt}-\%$ BSG powder and $5 \mathrm{wt}-\%$ distilled water were mixed thoroughly in a mortar to obtain homogeneous mixtures. The wet powder mixture was pressed uniaxially in a hydraulic press to obtain green compacts of diameter $20 \times 2 \mathrm{~mm}$ thickness; the compacts were dried overnight in an oven at $75^{\circ} \mathrm{C}$. The composition was maintained constant by mixing similar particle sizes of PVW and BSG $(<38 \mu \mathrm{m}$ PVW to $<38 \mu \mathrm{m} \mathrm{BSG,}<100 \mu \mathrm{m}$ PVW to $<100 \mu \mathrm{m}$ BSG, $<250 \mu \mathrm{m}$ PVW to $<250 \mu \mathrm{m} \mathrm{BSG).} \mathrm{These} \mathrm{samples}$ are labelled as shown in Table 1.

Sintering was performed on dry samples at temperatures in the range 800 to $1200^{\circ} \mathrm{C}$ under direct heating conditions (placing powder compacts into the furnace preheated at the sintering temperature) for $30 \mathrm{~min}$ followed by cooling in air to room temperature (RT). No visible cracks were found on the samples after cooling to RT. Density and water absorption (WA) measurements were performed by Archimedes' method using the American Society for Testing and Materials standard procedure (C373-88). Samples were prepared for image analysis by grinding them to a $3 \mu \mathrm{m}$ finish, by means of fine silicon carbide paper, followed by cleaning in distilled water using an ultrasonic cleaning bath. Optical microscopic images were analysed for pore size and pore volume using ImageJ open source software. Backscattered images from the prepared samples were taken using an ESEM Quanta 200 FEI NL scanning electron microscope (SEM).

The crystalline phases were studied by means of X-ray diffraction on powdered samples (Bruker AXS D8 Advance, operating with $\mathrm{Cu} K_{\alpha}$ radiation) supported by the Match! program package (Crystal Impact GbR) for semiautomatic phase identification.

\section{Results and discussion}

Figure $1 a$ shows the densities of powder compacts GC38, GC100 and GC250 sintered at temperatures between 800 and $1200^{\circ} \mathrm{C}$. After sintering at $800^{\circ} \mathrm{C}$, all powder compacts had similar low densities, indicating no significant viscous flow densification. However, above $850^{\circ} \mathrm{C}$, all samples exhibited a drastic density change; sample GC38, as an example, rose from $\sim 1.9 \mathrm{~g} \mathrm{~cm}^{-3}$ at $800^{\circ} \mathrm{C}$ to $\sim 2.7 \mathrm{~g} \mathrm{~cm}^{-3}$ at $850^{\circ} \mathrm{C}$.

In good agreement with the classical theories of viscous flow sintering, ${ }^{13}$ the densification was found to be more effective with fine particles $(<38 \mu \mathrm{m})$ due to their higher specific surface energy; in fact, compacts made from coarser particles $(<100$ and $<250 \mu \mathrm{m})$ reached a density of $\sim 2.7 \mathrm{~g} \mathrm{~cm}^{-3}$ by a further increase of sintering temperature

Table 1 Nomenclature of PVW + 10 wt-\% BSG samples

\begin{tabular}{lll}
\hline Particle size & Composition & Abbreviation \\
\hline$<38 \mu \mathrm{m}$ & PVW+10 wt-\% BSG & GC38 \\
$<100 \mu \mathrm{m}$ & PVW+10 wt-\% BSG & GC100 \\
$<250 \mu \mathrm{m}$ & PVW+10 wt-\% BSG & GC250 \\
\hline
\end{tabular}

up to 875 and $900^{\circ} \mathrm{C}$. Alternatively, at a given temperature of $850^{\circ} \mathrm{C}$, an increase in the annealing time to 45 and 60 min was necessary for GC100 and GC250 samples to reach maximum density of $2.7 \mathrm{~g} \mathrm{~cm}^{-3}$, as demonstrated in Fig. 2. The time necessary to achieve similar densities can vary depending on the particle size distribution, extent of viscous flow at the given temperature and crystallisation ability of the material. In GC38 powder compacts, due to higher surface area, maximum densification occurred within $15 \mathrm{~min}$ of annealing time at $850^{\circ} \mathrm{C}$, and the density remained constant up to $120 \mathrm{~min}$. A similar effect was observed by Pascual et al. ${ }^{14}$ in a glass system sintered at different holding times and temperatures. In the case of GC100 and GC250 samples, because of the lower surface area and large pore sizes in the green compacts, the time taken to attain maximum density was recorded as $45 \mathrm{~min}$ for $\mathrm{GC} 100$ and $60 \mathrm{~min}$ for $\mathrm{GC} 250$ at the given temperature. Reducing the time required to attain densification is important from the industrial process point of view for optimising the production rate and to reduce energy costs.

The enhancement of densification, passing from 800 to $850-900^{\circ} \mathrm{C}$, led to a remarkable decrease of WA, as illustrated by Fig. $1 b$. In particular, the densest samples had a WA $<1 \%$.

Remarkably, as shown in Fig. $1 a$, treatments at temperatures above $900^{\circ} \mathrm{C}$ resulted in samples with a much lower density, especially from powders of intermediate size (GC100 samples). The decrease of density corresponded to a dramatic increase of WA (up to $50 \%$ ), as illustrated in Fig. $1 b$. This phenomenon was attributed to the formation of a multitude of microsized pores, ${ }^{15}$ particularly for GC38 samples, as illustrated in Fig. 3. In other words, while the densest sample exhibited only a system of isolated pores (Fig. $3 a$ ), the direct heating above $900^{\circ} \mathrm{C}$ resulted in the development of glass based foams (Fig. 3b) despite the absence of additives that could generate gasses by decomposition/oxidation reactions in the pyroplastic mass of softened glass particles undergoing sintering (glass based foams are well known to be developed by the addition of $\mathrm{C}, \mathrm{SiC}$ or carbonates) ${ }^{8}$.

Figure 4 reports quantitative data on pore volume and pore size obtained by analysing SEM images. Figure $4 a$ shows that a pore volume of $\sim 5 \%$ was observed in sample GC38 at sintering temperatures of 850 and $875^{\circ} \mathrm{C}$; this value rose to $\sim 65$ vol. $-\%$ at $950^{\circ} \mathrm{C}$. After sintering at $950^{\circ} \mathrm{C}, \sim 50$ vol.- $\%$ porosity was observed in sample GC100, but only 10 vol.- $\%$ porosity was measured in sample GC250. In Fig. 4b, the pore size is presented for samples processed at different temperatures. An average minimum pore size was recorded for the different particle size samples at their maximum densities (shown in Fig. 1a), and an increasing pore size was also observed outside this range. Thus, glass ceramics processed at $950^{\circ} \mathrm{C}$ are interesting for applications requiring highly porous materials but low pore size.

The formation of micron sized pores presented in Figs. 3 and 4 was accompanied by other microstructural changes, inferred from X-ray diffraction analysis. Figure $5 a$ shows that the densest samples, fired below $950^{\circ} \mathrm{C}$, had limited crystallinity. The small peaks are consistent with the main diffraction lines of diopside, that is, $\mathrm{Ca}-\mathrm{Mg}$ silicate $\left(\mathrm{CaMgSi}_{2} \mathrm{O}_{6}, \mathrm{PDF} \# 71-1496\right.$, peaks labelled with " $\mathrm{A}$ "), and gehlenite, a Ca alumino-silicate $\left(\mathrm{Ca}_{2} \mathrm{Al}_{2} \mathrm{SiO}_{7}, \mathrm{PDF} \# 74-1607\right.$, peaks 

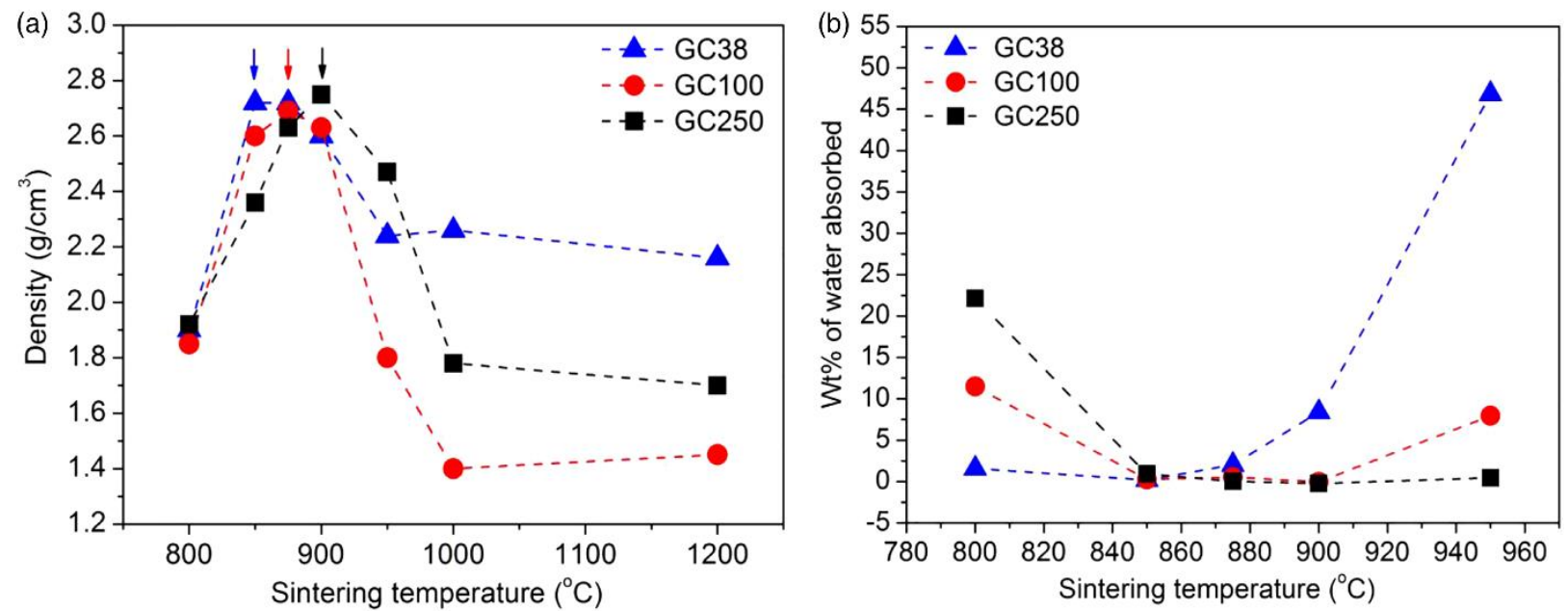

1 Comparison of influence of sintering temperature on a density and $b$ WA of PVW $+10 \mathrm{wt}-\%$ BSG sintered GCs made with different particle sized powders

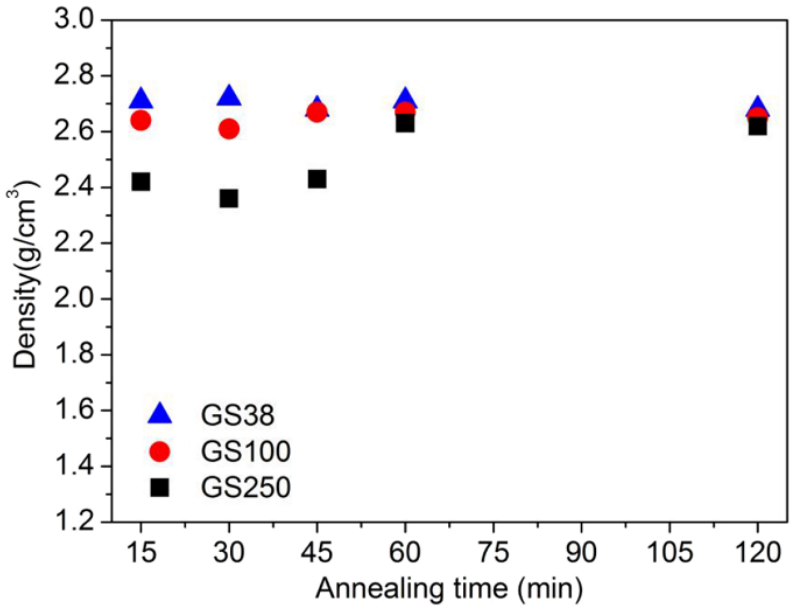

2 Density values of GC38, GC100 and GC250 samples sintered at $850^{\circ} \mathrm{C}$ for different holding times

labelled with "B") belonging to the family of melilites. The sample from finest powders, GC38, appears the least crystalline, but this is attributable only to the above discussed promotion of viscous flow sintering: an enhanced densification removed many free glass surfaces, well known to catalyse the precipitation of silicates and alumina-silicates (by a surface nucleation mechanism). ${ }^{16}$ This explanation is confirmed in Fig. $5 b$, illustrating a sensible increase of crystallisation degree with increasing sintering temperature; the almost flat background of the pattern for GC38 sintered at $950^{\circ} \mathrm{C}$ is an evidence of limited residual amorphous phase.

In GC38 sintered at $950^{\circ} \mathrm{C}$, the two phases detected in Fig. $5 a$ coexist with other more prominent crystalline phases, as shown by the upper pattern of Fig. $5 b$ and as presented in more detail in Fig. $6 b$. The strongest peaks are attributed to pseudowollastonite $\left(\mathrm{CaSiO}_{3}\right.$, PDF\#74-0874) and anorthite $\left(\mathrm{Ca}_{2} \mathrm{Al}_{2} \mathrm{Si}_{2} \mathrm{O}_{8}\right.$, PDF\#861705). Minor peaks are associated with pyroxene $\left(\left(\mathrm{Ca}_{0.75} \mathrm{Na}_{0.249} \mathrm{Fe}_{0.018}\right)\left(\mathrm{Mg}_{0.937} \mathrm{Fe}_{0.063}\right) \mathrm{Si}_{2} \mathrm{O}_{6}, \quad\right.$ PDF\#860003), wollastonite (a further variant $\mathrm{CaSiO}_{3}$, actually known as "para-wollastonite", PDF\#76-0925) and gehlenite (as previously found). The effective presence of pure diopside is unlikely, considering that $\mathrm{CaMgSi}_{2} \mathrm{O}_{6}$ is only a variant of the complex series of solid solutions known as pyroxenes; the pyroxene phase reported in Fig. 6 could be seen as the result of the incorporation of iron (and sodium) ions in the diopside structure.

The correlation between crystallisation and porosity in glass ceramics has been the object of several investigations. ${ }^{17,18,19}$ It must be pointed out that the observed porosity evolution in the present samples could be due to the superposition of different effects, as outlined in the next paragraphs.

(i) Trapping of internal porosity - High heating rates generally imply a faster heating at the surface of samples. Such surface can form a nonporous viscous layer blocking the release of gases from the bulk of the material, creating (close) porosity in the interior of the sample.

(ii) Crystallisation induced porosity - As discussed by Karamanov and Pelino, ${ }^{17}$, when a glass undergoes devitrification, the local reduction of volume associated with the formation of crystals creates voids. These voids are not compensated by the flow of the residual amorphous phase due to the increase of apparent viscosity (a glass embedding rigid, crystal inclusion is less prone to flow than the parent glass, without inclusions). The effect obviously depends on the composition, that is, on the specific volume changes of different phases: the same authors calculated a crystallisation induced pore volume of $4-4.5 \%$ for wollastonite and $10-12 \%$ for diopside (both phases effectively developed in our system). Karamanov and Pelino ${ }^{17}$ and Bernardo et al. ${ }^{18}$ also mentioned crystallisation stresses arising from differences in coefficient of thermal expansion between glass and crystals and from the anisotropy of the coefficient of thermal expansion of silicates, which could force the expansion of pores. Bernardo et al. ${ }^{18}$ showed that a glass undergoing sintering and crystallisation, similar to the present results, could exhibit a quite surprising, significant decrease of density, from 2.7 to $2.1 \mathrm{~g} \mathrm{~cm}^{-3}$, with increasing sintering time.

(iii) Evolution of gasses from modification of the oxidation state - Glasses comprising iron oxide may present a "bloating" effect, due to oxygen release, in turn caused by the reduction of $\mathrm{Fe}^{3+}$ 

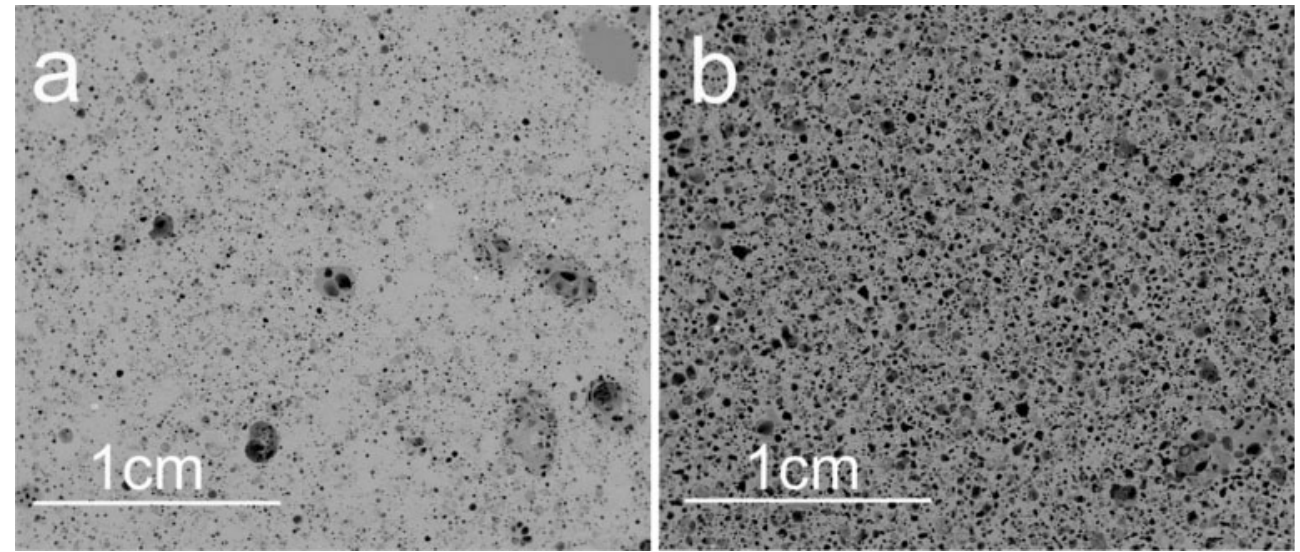

3 Optical microscopy images of GC38 compacts sintered at $a 850^{\circ} \mathrm{C}$ and $b 950^{\circ} \mathrm{C}$, both for $30 \mathrm{~min}$, showing increase of porosity with temperature
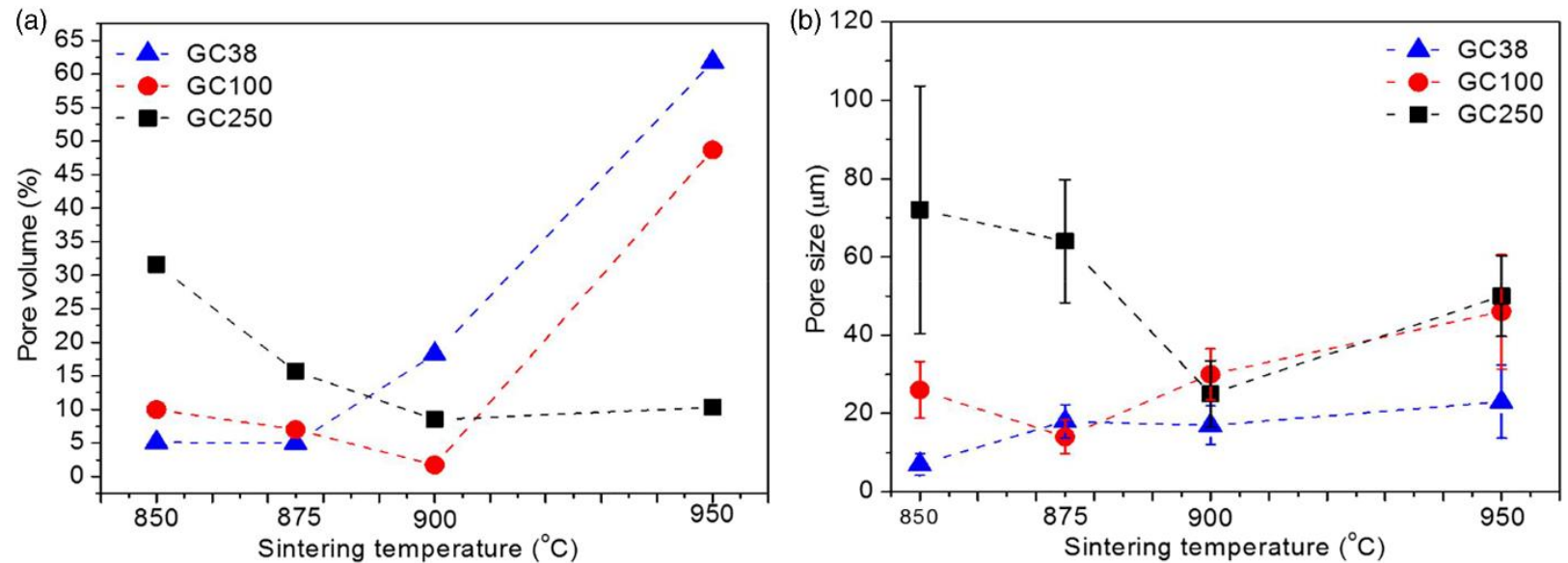

4 Influence of processing temperature on a pore volume and $b$ pore size for samples GC38, GC100 and GC50
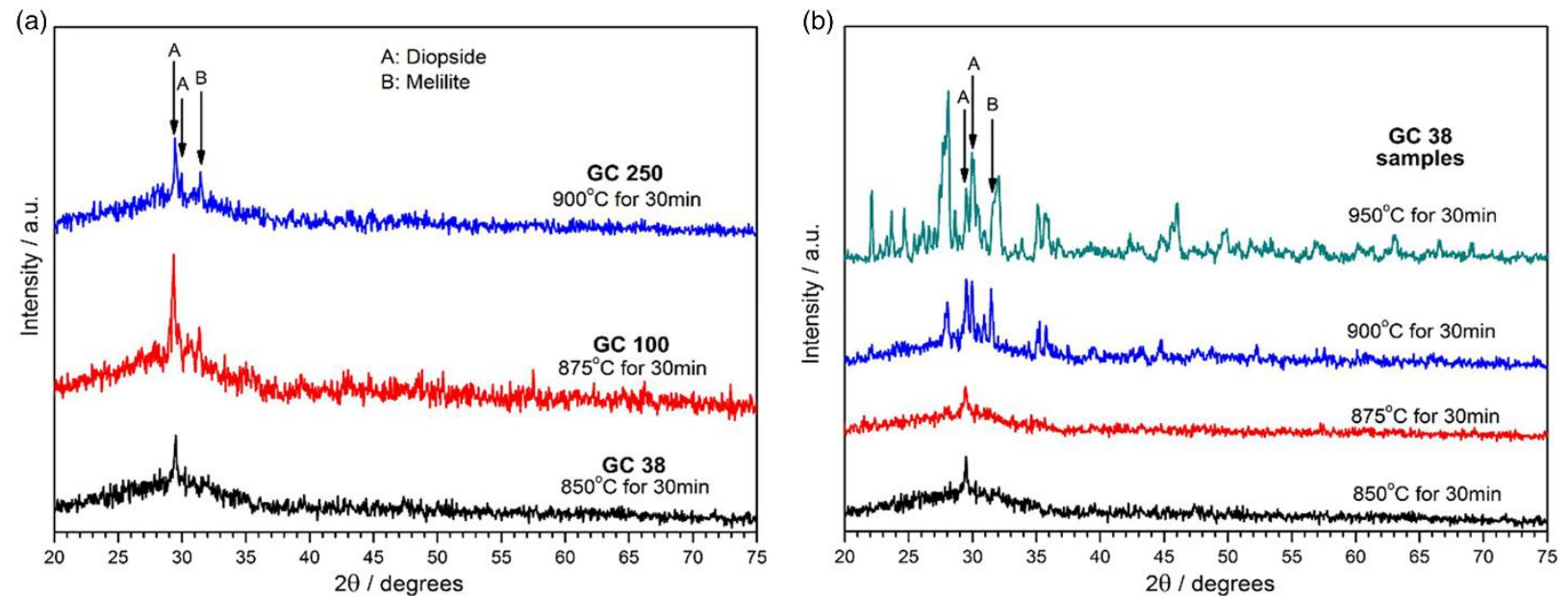

5 a X-ray diffraction patterns of densest samples, fired at different temperatures, depending on granulometry, and $b$ phase evolution of GC38 samples with increasing sintering temperature

(ferric) into $\mathrm{Fe}^{2+}$ (ferrous) ions (the overall reaction is $2 \mathrm{Fe}_{2} \mathrm{O}_{3} \rightarrow 4 \mathrm{FeO}+\mathrm{O}_{2}$ ); this effect is the basis of recently developed highly porous glass ceramics ${ }^{8,19}$. The PVW glass contains more than $4.5 \mathrm{wt}-\%$ $\mathrm{Fe}_{2} \mathrm{O}_{3}^{11}$; ferrous ions were effectively found in the pyroxene phase, detected for the (highly porous) sample sintered at $950^{\circ} \mathrm{C}$.
These three mechanisms could have individually or collectively been activated by the addition of BSG glass, leading to the formation of a porous glass ceramic. In fact, EDX mapping (not shown) of the backscattered SEM images in Fig. $7 a$ and $b$ revealed that pores concentrated in the amorphous zones corresponding to former BSG glass particles. 


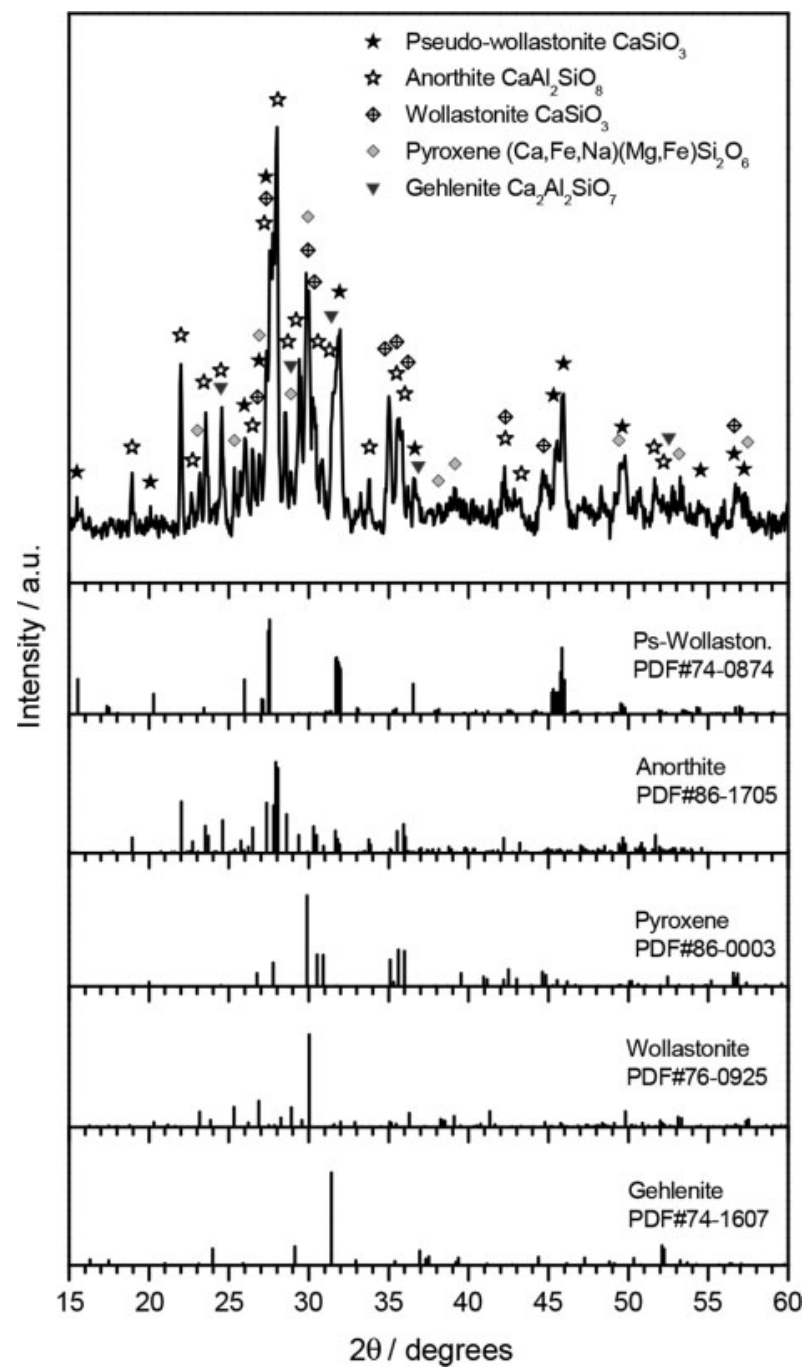

6 Detailed X-ray diffraction of GC38 sample sintered at $950^{\circ} \mathrm{C}$
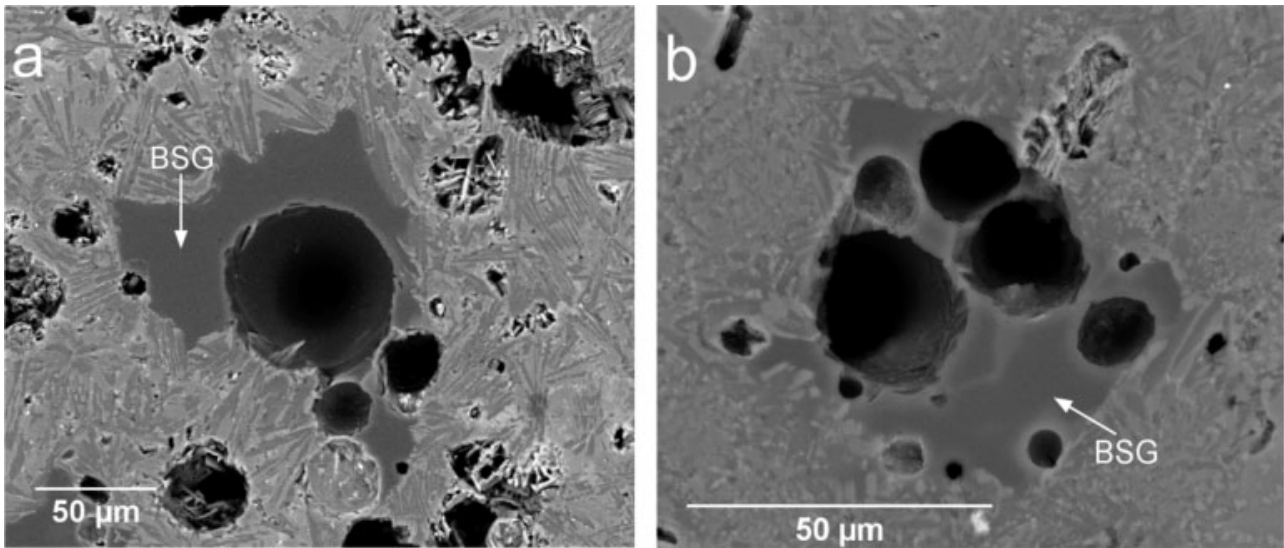

7 Backscattered SEM images of glass ceramic microstructures showing rounded pores in a sample GC250 sintered at $900^{\circ} \mathrm{C}$ and $b$ sample $\mathrm{GC} 100$ sintered at $875^{\circ} \mathrm{C}$

The addition of BSG is thought to favour all the proposed mechanisms of pore formation, and the presence of alumina in the composition could have made BSG less sensitive to crystallisation ${ }^{20}$. The presence of BSG's low viscosity phase along with less viscous PVW could i) promote the sealing of internal porosity by enhanced viscous flow, ii) promote ionic interdiffusion and favour anisotropic crystal growth (the effect is well known for mullite ${ }^{21}$; a confirmation of the effect in our system may be found in the fibrous crystals around the pores observed in Fig. 7a) and iii) favour the bloating, considering the key role of viscosity in the development of porosity. ${ }^{13,17,20}$

The exact balance between the different mechanisms responsible for pore formation should be clarified performing additional experiments, involving glasses of different composition. However, the present results are of relevance for the development of technical (porous) glass 
ceramics from this particular combination of wastes. For example, the possibility of sintering PVW $+10 \mathrm{wt}-\%$ BSG within $30 \mathrm{~min}$ to form a porous, highly crystalline, glass ceramic is an attractive approach for developing materials for thermal insulation applications in the construction industry. Pore size and volume can be engineered by changing particle size and sintering temperature. This knowledge is relevant to industry to realistically consider waste derived glass ceramics for developing construction application oriented materials for thermal and sound insulation in modern housing.

\section{Conclusions}

Mixtures of PVW +10 wt- $\%$ BSG of different particle sizes were successfully sintered and crystallised to form glass ceramics by direct heating and normal cooling in air to RT. The glass ceramics made from particles of size $<38 \mu \mathrm{m}$ showed densification within $15 \mathrm{~min}$ at $850^{\circ} \mathrm{C}$. Increasing the sintering temperature led to an increase in the volume of micron sized porosity in all compacts. The balance between densification by viscous flow and crystallisation, the formation of voids induced by crystallisation and the reduction of iron oxide were suggested to be responsible for the drastic porosity increase in sintered compacts. Glass ceramics made from particles $<38 \mu \mathrm{m}$ developed 65 vol.- $\%$ micron sized porosity with a pore size of $\sim 20 \mu \mathrm{m}$ when sintered at $950^{\circ} \mathrm{C}$. Potential industrial applications of the porous glass ceramics, for example, as building materials, should be facilitated by the cost effective fabrication process.

\section{Acknowledgements}

The authors would like to thank Dr. D. Deegan from Tetronics Ltd., for PVW and discussions during preparation of this paper. The support of the European Community's Seventh Framework Programme (FP7) through a Marie-Curie Research Training Network ("GlaCERCo" PITN-GA-2010-264526) is gratefully acknowledged.

\section{References}

1. European Waste Catalogue 19-04-07, http://www.environmentagency.gov.uk/static/documents/GEHO1105BJVS-e-e.pdf.

2. J. Tim, http://www.environmental-expert.com/articles/the-use-ofthermal-plasma-technology-for-treating-air-pollution-control-residues283230/view-comments, 2012, Waste Advantage Magazine. Date: 07.05.2015.
3. http://epp.eurostat.ec.europa.eu: 'Municipal waste generation and treatment, by type of treatment method', tsdpc240. Date: 15.11.2012.

4. H. K. Lam, A. W. M. Ip, J. P. Barford and G. McKay: 'Use of incineration MSW ash: a review', Sustainability, 2010, 2, 1943-1968.

5. E. Gomez, D. Amutha Rani, C. R. Cheeseman, D. E. Deegan, M. L. H. Wise and A. R. Boccaccini: 'Thermal plasma technology for the treatment of wastes: a critical review', J. Hazard. Mater., 2009, 161, 614-626.

6. R. D. Rawlings, J. P. Wu and A. R. Boccaccini: 'Glass-ceramics: their production from wastes-a review', J. Mater. Sci., 2006, 41, 733-761.

7. W. E. Lee, M. I. Ojovan, M. C. Stennett and N. C. Hyatt: 'Immobilisation of radioactive waste in glasses, glass composite materials and ceramics', Adv. Appl. Ceram., 2013, 105, 3-12.

8. R. K. Chinnam, A. A. Francis, J. Will, E. Bernardo and A. R. Boccaccini: 'Review. Functional glasses and glass-ceramics derived from iron rich waste and combination of industrial residues', J. Non-Cryst. Solids, 2013, 365, 63-74.

9. V. M. Garcia, G. Avila, S. Martinez, R. Terradas and J. M. Nogues: 'Acoustic barriers obtained from industrial wastes', Chemosphere, 2008, 72, 1098-1102.

10. A. V. P. Albertini, A. L. S. Reis, F. R. R. Telesh, J. C. Souza, J. L. RolimFilho and V. N. Freire: 'The new flow system approach in packed bed reactor applicable for immobilized enzyme', J. Mol. Catal. B, 2012, 79B, 1-7.

11. J. A. Roether, D. J. Daniel, D. A. Rani, D. E. Deegan, C. R. Cheeseman and A. R. Boccaccini: 'Properties of sintered glass-ceramics prepared from plasma vitrified air pollution control residues', J. Hazard. Mater., 2010, 173, 1177-1183.

12. R. K. Chinnam: 'Functional glasses and glass-ceramics derived from industrial wastes', 2014, Doctoral dissertation, University of Erlangen-Nuremberg, Erlangen, Germany.

13. G. W. Scherer: 'Sintering of low-density glasses: I', Theory, J. Am. Ceram. Soc., 1977, 60, 236-239.

14. M. J. Pascual, A. Duran and L. Pascual: 'Sintering process of glasses in the system $\mathrm{Na}_{2} \mathrm{O}-\mathrm{B}_{2} \mathrm{O}_{3}-\mathrm{SiO}_{2}$ ', J. Non-Cryst. Solids., 2002, 306, 58-69.

15. C. R. Cheeseman, A. Makinde and S. Bethanis: 'Properties of lightweight aggregate produced by rapid sintering of incinerator bottom ash', Resour. Conserv. Recycl., 2005, 43, $147-162$.

16. E. Bernardo: 'Fast sinter-crystallization of a glass from waste materials', J. Non-Cryst. Solids, 2008, 354, 3486-3490.

17. A. Karamanov and M. Pelino: 'Induced crystallization porosity and properties of sintered diopside and wollastonite glassceramics', J. Eur. Ceram. Soc., 2008, 28, 555-562.

18. E. Bernardo, R. Castellan and S. Hreglich: 'Sintered glass-ceramics from mixtures of wastes', Ceram. Int., 2007, 33, 27-33.

19. I. Ponsot and E. Bernardo: 'Self glazed glass ceramic foams from metallurgical slag and recycled glass', J. Clean. Prod., 2013, 59, 245-250.

20. R. K. Chinnam, A. R. Boccaccini, E. Bernardo and H. Epstein: 'Glass-ceramic composites from borosilicate glass and aluminarich residues', Int. J. Appl. Ceram. Technol., 2015, 12, 19-27.

21. S. H. Hong and G. L. Messing: 'Anisotropic grain growth in diphasic-gel-derived titania-doped mullite', J. Am. Ceram. Soc., 1998, 81, 1269-1277. 